V. 12 N. 3

SET-DEZ 2016

ISSN 2317-6172

Recebido: 27.05 .2013

Aprovado: 23.03.2016

DOI: http://dx.doi.org/10.1590/ 2317-6172201625

1 Advogado São Paulo - SP - Brasil

\section{Reflexões sobre as possíveis razões para não ocorrer uma reforma tributária no Brasil}

REFLECTIONS ON THE POSSIBLE REASONS FOR NOT OCCURRING A TAX REFORM IN BRAZIL

Daniel Leib Zugman'

\section{Resumo}

Este texto analisa o problema da reforma tributária brasileira sob a perspectiva do Direito e Desenvolvimento. Pretende explicar por que, apesar de existir aparente consenso sobre a necessidade de reforma, o sistema tributário do país não sofre alterações estruturais. Utilizam-se textos nacionais e estrangeiros que tratam de política e reforma tributária e da relação entre Direito e Desenvolvimento. São apontados os principais atores, obstáculos e resultados de tentativas de reforma tributária já realizadas. Aparentemente, o problema vem sendo enfrentado como de natureza meramente técnica, quando, na verdade, a não ocorrência da reforma pode estar mais relacionada a divergências políticas existentes entre estados, municípios e a União. Nesse contexto, as lições do Direito e Desenvolvimento sugerem que reformas jurídicas amplas e radicais tendem a fracassar. Procura-se demonstrar as amarras institucionais que dificultam o acontecimento de profunda reestruturação do sistema de tributos brasileiro e sugerem-se, exemplificativamente, estratégias alternativas incrementais que podem contribuir para o sucesso de futuras medidas modificativas.

\section{Palavras-chave}

Reforma tributária; Direito e Desenvolvimento.

\begin{abstract}
This paper aims at analyzing the Brazilian tax reform issue from a Law and Development perspective. The goal is to explain the reasons why, despite the existence of apparent consensus on the need for a tax reform in the country, up to now the Brazilian tax system has not suffered structural changes. We have used domestic and foreign texts regarding tax policy and tax reform, as well as texts drafted by scholars who analyze the relation between Law and Development. We point out stakeholders, obstacles and results of previous attempts to reform the Brazilian tax system. Apparently, up to the moment the tax reform issue has been addressed as being purely technical, while the difficulties for implementing a tax reform may be more closely related to political disagreements. The Law and Development lessons suggest that broad and radical reforms tend to fail. In this context, we demonstrate the institutional shackles that hinder the occurrence of a profound restructuring of the Brazilian tax system and suggest, not exhaustively, incremental alternative strategies that may be helpful in future attempts to reform the Brazilian tax system.
\end{abstract}

\section{Keywords}

Tax Reform; Law and Development. 


\section{INTRODUÇÃO E DELIMITAÇÃO DOS OBJETIVOS}

O tema da reforma tributária no Brasil sempre foi envolvido por aparente consenso: todos concordam que o sistema tributário pátrio é problemático e que, portanto, precisa ser modificado. A despeito disso, as numerosas emendas constitucionais e propostas legislativas já criadas com esse objetivo não tiveram êxito. A maioria delas não chegou sequer a ser aprovada no Congresso Nacional ou, quando isso aconteceu, não se conseguiu alterar significativa e positivamente o sistema em funcionamento. Pior: em diversas oportunidades ocorreu aumento da carga tributária e da complexidade do sistema, ao contrário do que se prometia obter com tais reformas.

Para os propósitos deste artigo, "reforma tributária" corresponde a uma ampla e estrutural modificação do sistema de tributos brasileiro, promovida por meio de reforma legislativa em nível de lei complementar ou por emenda constitucional, cujos efeitos sejam, principalmente, a redução da carga tributária e da complexidade das normas tributárias.

Tendo isso em vista, o objetivo deste trabalho é explicitar, a partir da literatura do Direito e Desenvolvimento (Law and Development), por que as diversas tentativas de reformar o sistema tributário brasileiro fracassaram, culminando, quase sempre, na piora do sistema e na majoração da carga tributária.

Para tanto, este texto está organizado em cinco tópicos, além deste. No segundo tópico o percurso metodológico trilhado é narrado, de modo que se permita ao leitor verificar se os resultados obtidos estão amparados por premissas e métodos adequados.

No terceiro tópico o problema da reforma tributária é brevemente apresentado, indicando-se quem são os principais atores, obstáculos enfrentados e resultados de tentativas de reforma já realizadas.

No quarto tópico são trazidas a lume lições da literatura do "campo"1 denominado Direito e Desenvolvimento, que sugerem os motivos pelos quais reformas jurídicas nem sempre conduzem aos resultados esperados.

No quinto tópico os ensinamentos dos autores que tratam da questão do Direito e Desenvolvimento são aplicados ao sistema tributário pátrio e, em especial, a path dependence é minudenciada de molde a demonstrar as amarras que dificultam o processo de reforma tributária no país.

Por fim, no último tópico são apresentadas considerações finais que podem contribuir para o aprofundamento do debate acerca da reforma tributária brasileira e são sugeridos

1 Alguns autores como Brian Z. Tanamaha ressalvam que o Direito e Desenvolvimento não pode ser considerado um campo, pois lhe falta coerência interna: "Em vez disso, o trabalho do Direito e Desenvolvimento é mais bem visto como uma aglomeração de projetos perpetuados por atores motivados e que contam com o apoio de financiamentos" (TANAMAHA, 2010, p. 179).

2 O conceito de path dependence será estudado detalhadamente mais adiante. Por ora, pode ser traduzido como "inércia institucional". 
caminhos alternativos que podem contribuir para o sucesso de eventuais reformas. Ressalve-se que tais sugestões não são exaustivas e podem ser frustrantes caso se esperem delas fórmulas para o sucesso ou a via sacra para as soluções que nosso sistema tributário demanda. Este texto não tem a pretensão de oferecer tais respostas, mas apenas apresentar alguns dos motivos que podem explicar a não ocorrência de ampla reforma e, subsidiariamente, recomendar rotas alternativas que a longo prazo podem se tornar frutíferas.

\section{Nota METOdológica}

Este é um artigo teórico que utiliza textos de autores que estudam as relações entre Direito e Desenvolvimento para analisar o problema prático da reforma tributária brasileira. Além dessas obras, também serviram de base artigos e livros de conhecidos doutrinadores do Direito Tributário, especialmente a obra Tributação e desenvolvimento, coordenada por Eurico Marcos Diniz de Santi (2011), que reúne textos de vários autores que relacionam o campo tributário com a questão do desenvolvimento.

Durante a redação deste paper também sentiu-se a necessidade de consultar autores que lidassem com o tema da reforma tributária sob perspectivas não estritamente jurídicas. A obra Crise, reforma e desordem do sistema tributário nacional, do professor Fabrício Augusto de Oliveira (1995), da Fundação João Pinheiro, o livro Lessons of tax reform, editado pelo Banco Mundial (WORLD BANK, 1991), o qual relata experiências de reformas tributárias em diversos países, bem como o texto "Taxation and development”, do professor Richard Bird (2010), da Universidade de Toronto, foram fontes de pesquisa úteis.

Finalmente, o relatório de pesquisa "Reforma tributária viável: simplificação, transparência e eficiência”, elaborado pelo Núcleo de Estudos Fiscais da Escola de Direito de São Paulo da Fundação Getulio Vargas (2010), foi fundamental. Os textos, entrevistas e demais dados empíricos confeccionados e coletados pelo Núcleo constituíram material rico e fecundo para o desenvolvimento das ideias a seguir apresentadas.

\section{REFORMA TRIBUTÁria NO BRASil: APARENTE CONSENSO}

Estudiosos do Direito Tributário, economistas, políticos, empresários e cidadãos em geral parecem compartilhar a ideia de que o sistema tributário brasileiro precisa sofrer ampla reforma. Pode-se dizer com José Souto Maior Borges que a “[...] Reforma Tributária [...] representa uma aspiração nacional praticamente unânime” (BORGES, 1985, p. 53).

Além disso, como ensina Eurico Marcos Diniz De Santi, há também relativa convergência em relação aos problemas e expectativas sobre as premissas norteadoras de uma reforma tributária. São elas: "simplicidade, eliminação da cumulatividade dos impostos indiretos, redução da tributação sobre o trabalho, eliminação da tributação sobre o investimento 
e transparência do valor do tributo para o contribuinte de fato (econômico)" (SANTI, 2012, p. 56).

Embora esse "consenso" aparentemente exista, as motivações, declaradas ou não, que levam cada grupo interessado a chegar à mesma conclusão são as mais diversas. Empresários, regra geral, querem a redução da carga tributária e a simplificação do sistema. Economistas costumam apontar as distorções que a dinâmica tributária existente causa na economia. Políticos, de um lado, por vezes ecoam as diversas vozes do quadro social nacional, mas, de outro, buscam geralmente aumentar a arrecadação tributária para os estados e municípios que representam.

O ensinamento de Aires Fernandino Barreto corrobora o argumento supra:

Todos preconizam e aceitam uma reforma tributária: a União, desde que cresça a sua fatia no todo; os Estados-membros, desde que aumentem suas receitas, os Municípios desde que possam contar com mais recursos; no outro lado, sozinho [...] o espoliado contribuinte, que, na contramão, quer redução de tributos [...] (BARRETO, 2005, p. 2).

Obviamente, o panorama acima desenhado é uma simplificação do complexo tecido social brasileiro, mas é o suficiente para demonstrar os diferentes interesses por trás do "consenso” acerca da reforma tributária.

E essa aparente concordância já vem de longa data. Não por outro motivo, a história dos tributos no Brasil é recheada de tentativas de reforma. José Roberto Vieira (2011) recorda as Emendas n. 05/1961 e n. 18/1965, à Constituição de 1946, ambas promovendo "reformas tributárias"; na sequência, o próprio texto da Carta Magna de 1967, logo alterado pela Emenda n. $01 / 1969$, os dois diplomas também apresentando reformas ao sistema constitucional tributário; e, outrossim, o novo capítulo do Sistema Tributário da Constituição de 1988, que, tal qual as Leis Maiores precedentes, não escapou de introduzir reformas, como a da Emenda n. 42/2003; e isso sem mencionar as numerosas propostas de emendas constitucionais e leis complementares.

A mais ampla e recente tentativa de reforma é aquela veiculada pela Proposta de Emenda Constitucional (PEC) n. 233, de 28.02.2008, de iniciativa do Poder Executivo e que tramita no Congresso Nacional apensada à PEC n. $31 / 2007$.

A despeito das nobres intenções dos reformadores, ${ }^{3}$ as expectativas em relação aos efeitos dessa PEC, se eventualmente aprovada, não são as mais positivas. Isso se deve ao fato de

3 Vejam-se alguns trechos da Exposição de Motivos assinada pelo ministro da Fazenda: "Os objetivos principais da Proposta são: [...] avançar no processo de desoneração tributária e eliminar distorções que prejudicam o crescimento da economia brasileira e a competividade de nossas empresas, principalmente no que diz respeito à chamada 'guerra fiscal' entre os Estados'; [...] estimular a atividade econômica e a competividade do País, através da racionalização e simplificação dos tributos, e promover a justiça social $[\ldots] "$. 
que as diversas reformas realizadas no país não tiveram sucesso, ou pelo menos não cumpriram os objetivos a que declaradamente se propuseram. É o que leciona Souto Maior Borges:

Nas experiências de reforma tributária, identifica-se, sempre, em seu ponto terminal, a frustração de legítimas expectativas nacionais quanto aos seus benefícios. Ela é ingenuamente visualizada como o modo de instauração do paraíso fiscal na terra, remédio infalível para todos os males que enfermam o sistema tributário nacional.

$[\ldots]$

Se a essência de um fenômeno é a sua invariância, a essência da reforma tributária, sob a falsa aparência de aperfeiçoamento do sistema, é o aumento da carga tributária. Esse aumento é o que sempre resta da experiência do passado. O que fica do que passou. Essa lição não é porém considerada na análise da reforma. (BORGES, 2011, p. 383, grifo nosso).

Isso posto, pode-se dizer que a história das reformas tributárias no país é marcada por intenções, em grande medida, legítimas por parte dos reformadores, pois os objetivos declarados são quase sempre sedutores. Geralmente, pretende-se a simplificação do sistema, o que parece estar em harmonia com as aspirações da maior parte da população. Entretanto, é igualmente uma história de contradições, uma vez que os resultados obtidos são invariavelmente marcados pelo desapontamento: a elevação do fardo dos tributos e o aumento da complexidade do sistema.

Sobejam razões, portanto, para desconfiar do êxito da PEC 233/2008 e de quaisquer eventuais tentativas radicais de reforma tributária pela via legislativa.

Ante o exposto, surgem questionamentos inquietantes: se há convergência no sentido de que é necessário reformar o sistema tributário pátrio, e se já existiram numerosas experiências em diferentes momentos históricos e contextos políticos, por que a maior parte delas não teve êxito? Por que a via legislativa não tem sido efetiva na reformulação do sistema tributário?

\section{Direito e Desenvolvimento e os desafios de uma reforma jurídica}

As lições do Direito e Desenvolvimento podem lançar alguma luz sobre o insucesso das várias reformas tributárias já intentadas no país. Sobre Direito e Desenvolvimento pode-se dizer, em apertada síntese, que se trata de campo de estudos que procura analisar as interações entre o sistema jurídico de determinado Estado e o grau de desenvolvimento deste. ${ }^{4}$

4 As concepções de desenvolvimento costumam variar entre crescimento econômico e desenvolvimento em um sentido mais amplo, que contempla a melhoria das condições de vida da população, de modo a lhe garantir maior livre arbítrio. Isso envolveria o incremento no acesso à educação, à saúde, ao debate político em sentido lato e a outros direitos básicos. 
Como explica Richard Swedberg (2005), professor do Departamento de Sociologia da Cornell University, Max Weber foi o precursor desse tipo de análise. Os estudos de Weber inspiraram os primeiros passos do Direito e Desenvolvimento, na década de 1960. Geralmente, os autores que trabalham com o tema costumam narrar um percurso histórico, dividindo o Direito e Desenvolvimento em diferentes fases, conforme o substrato teórico que norteou as iniciativas em prol do desenvolvimento ocorridas em cada momento. No entanto, para o propósito deste trabalho, importa apenas uma ideia que nasce a partir desse histórico: ${ }^{5}$ a chamada path dependence.

No princípio da década de 1990, a denominada Nova Economia Institucional ganhou força nos meios acadêmicos e nos foros de economistas, consolidando o jargão "instituições importam" (institutions matter). Douglass North (1990), principal expoente dessa doutrina e premiado com o Nobel de Economia, alega que as instituições são as regras de uma sociedade que regulam a interação humana. Seu intuito é reduzir as incertezas envolvidas nessa relação interativa, decorrentes da complexidade dos problemas que surgem em uma dada sociedade.

Assim sendo, a formatação institucional dita os limites em que os atores de uma sociedade operam, tornando inteligível a interconexão entre as regras do jogo e o comportamento dos diversos atores sociais. Desse modo, em economias desenvolvidas as instituições seriam adequadas ao aumento de produtividade e ao crescimento econômico, pois protegem eficientemente os direitos de propriedade, o que reduz os custos de transação, permitindo lucros maiores e expansão dos mercados. De outro lado, nos países em desenvolvimento, a ausência de um ambiente institucional fortalecido impõe uma série de custos para a realização da atividade econômica, o que desencoraja o aumento de produtividade e, consequentemente, inibe o desenvolvimento econômico e social.

A partir dessa interpretação da realidade surge a equação "bom direito + boa aplicação/ efetividade $=$ bons resultados econômicos" (good law + good enforcement $=$ good economic results $)$, baseada na ideia de que as economias desenvolvidas atingiram esse estágio em razão de suas instituições, especialmente dos direitos de propriedade bem protegidos. Destarte, para que os países em desenvolvimento alcançassem o mesmo patamar, deveriam adotar instituições similares e garantir o império do direito (rule of law), o que inexoravelmente conduziria ao desenvolvimento. Como diz Peter Evans, professor do Departamento de Sociologia da Universidade de Berkeley, Califórnia, o mote dessa corrente era: "[...] o que é replicável e transferível deve ser trazido à luz e compartilhado com os outros" (EVANS, 1995, p. 21). E dessa visão resultou a famigerada expressão one size fits all ("um tamanho serve para todos").

Nesse passo, organizações internacionais que antes destinavam a maior parte de seus financiamentos a projetos de infraestrutura, passaram a investir em reformas jurídicas e

5 Para mais informações, consultar Schapiro e Trubek (2012). 
institucionais. Em vários países em desenvolvimento, foram implementados projetos no modelo one size fits all, em que as instituições e instrumentos jurídicos de países desenvolvidos, como Estados Unidos e Inglaterra, eram transplantados a Estados em desenvolvimento.

Entretanto, essas reformas jurídicas não tiveram o êxito esperado. Conforme Schapiro e Trubek, “[...] os países mais fiéis às agendas reformistas, como Argentina e México, tiveram um desempenho menos expressivo do que os seus pares mais rebeldes, como China e Índia” (SCHAPIRO; TRUBEK, 2012, p. 40). Acrescente-se que muitas dessas reformas não foram sequer capazes de alterar a realidade que pretendiam modificar, sendo criadas leis e instituições sem aderência aos países em tela.

De forma geral, as reformas supramencionadas ignoraram a realidade local dos diversos países em que foram intentadas, fracassando no objetivo de promover o desenvolvimento. Não consideraram as culturas locais e as especificidades de cada sociedade e fecharam os olhos para as resistências políticas, sociais e econômicas que mudanças radicais poderiam vir a enfrentar.

De acordo com Katharina Pistor e Curtis Milhaupt (2008), professores da Columbia Law School, essas consequências foram frutos da visão de que o direito é uma dotação de fatores (endowment) politicamente neutra, que poderia ser transplantada de um local para outro. Mas, conforme argumentam, o direito, obviamente, é produto da interação humana.

Desta feita, os processos interativos de cada sociedade importam para a produção e a aplicação do direito. Estrutura de governo, natureza do sistema político, nível de educação, desigualdade socioeconômica, entre um sem fim de elementos, são algumas das peças do complexo mosaico sobre o qual o direito se instala. Nessa linha, Brian Tamanaha, professor da Washington University Law, afirma que os intelectuais e profissionais do Direito e Desenvolvimento aprenderam a lição e já reconhecem a importância do contexto e das condições locais. Entretanto, em suas palavras, "O que tolhe os projetos de Direito e Desenvolvimento repetidamente é a extrema inter-relação de tudo com todo o resto numa sociedade..." (TAMANAHA, 2010, p. 178).

Por esse motivo, de acordo com Mariana Prado e Michael Trebilcock (2009), professores da Toronto Law School, é muito difícil alterar instituições. Com o passar do tempo, as condições institucionais estabelecem o modo como a atividade econômica pode gerar retorno e crescimento, e, sendo essas condições já conhecidas, a tendência é que os benefícios decorrentes delas aumentem com o transcurso do tempo, já que cada vez mais atores investem numa certa maneira de fazer as coisas. Trata-se da denominada path dependence, ou inércia institucional. Não é possível saber, portanto, quais serão os resultados de alterações profundas, as quais podem comprometer a dinâmica de funcionamento de uma comunidade. Assim sendo, há um alto custo de se mudar a forma de ser das instituições.

A dificuldade de implementar reformas, todavia, não enfraquece a conclusão da Nova Economia Institucional no sentido de que as instituições importam. Como apontam Dani Rodrik, professor de Política Econômica Internacional da Harvard University, e Arvind Subramanian, consultor do Departamento de Pesquisa do Fundo Monetário Internacional, o elemento 
“instituições” é determinante e prevalente sobre os demais ("geografia” e "integração comercial”, por exemplo) para a questão do desenvolvimento (RODRIK; SUBRAMANIAN, 2003). A pergunta que interessa, portanto, não é se as instituições importam, mas as seguintes: quais instituições, exatamente, são desejáveis? E como promover mudanças naquelas já existentes, tendo em vista as resistências dos atores locais que se beneficiam com a manutenção do status quo?

A resposta é a mais incômoda possível: não se sabe. A verdade é que não há atalho que conduza ao progresso, não há instituições corretas que "dão certo" em qualquer local, e o desenvolvimento é produto de complexa interação de fatores praticamente inumeráveis. A despeito do panorama desanimador, há alguns caminhos que, a longo prazo, podem trazer algum êxito.

\section{I DesenVOlVimento COMO Descoberta: SUPERANDO A PATH DEPENDENCE POR MEIO DA} REPRODUÇÃO DE BOAS PRÁTICAS, DO EXPERIMENTALISMO GRADUAL E DO BYPASS INSTITUCIONAL Prado e Trebilcock (2009) sugerem duas estratégias para a implementação de reformas institucionais. A primeira é identificar quais instituições já dão certo em uma sociedade ou no mundo e tentar replicá-las localmente, de maneira adaptada aos objetivos que se pretende atingir e levando-se em consideração o contexto local. É verificar o que já funciona, o porquê desse bom funcionamento e procurar reproduzir esses pontos positivos de maneira customizada.

A segunda alternativa é reformar instituições existentes de maneira gradual, priorizando uma sequência de reformas a partir de um número pequeno delas, mas reconhecendo que futuramente modificações adicionais serão necessárias para reforçar as primeiras. Ou seja, uma reforma experimental e incremental.

Uma terceira forma possível é apontada por Mariana Prado (2011): o atalho institucional (institutional bypass). Essa estratégia é marcada por quatro características principais: 1) deixa a instituição tradicional em funcionamento; 2) cria uma rota alternativa para a prestação de serviços públicos ou funções governamentais (que se torna uma opção para os que usam esses serviços); 3) seu objetivo é ser mais eficiente ou funcional do que a instituição tradicional e; 4) altera um ponto específico do sistema (em vez de modificar o sistema inteiro).

\section{DA VisÃo PANORÂMICA À APROXIMAÇÃo COM A REALIDADE TRIBUTÁRIA BRASILEIRA}

Com relação ao sistema tributário, o que se pode afirmar a partir da revisão literária acima articulada é que, aparentemente, as tentativas de modificar o sistema de tributos brasileiro, como regra geral, não levaram em consideração a path dependence que nosso contexto político, social e econômico impõe. Tais reformas foram tratadas como politicamente neutras, 
ignorando-se o fato de que, como observado acima, cada parte interessada tem uma aspiração diferente quando se fala em reforma tributária.

Um exemplo nesse sentido é o da reforma tentada durante o Governo Collor. Como narram Sérgio de Azevedo e Marcus André Melo (1997), essa foi a primeira iniciativa ampla de proposta de reforma fiscal no período pós-Constituinte. Com a criação da Comissão Executiva da Reforma Fiscal (CERF), foi proposto um conjunto de medidas que passou a constituir os termos da discussão pública em torno da questão: a criação de um Imposto sobre Valor Agregado (a partir da fusão do IPI, ICMS e ISS) pago no destino; a desoneração plena das exportações; a eliminação de contribuições sociais, com a privatização parcial da previdência social; a criação de uma Contribuição sobre Transações Financeiras (adotada depois como IPMF e CPMF) e, para custear a Previdência, a criação de um imposto sobre ativos e de impostos seletivos sobre energia elétrica e combustíveis, entre outros.

Os trabalhos da CERF não chegaram a ser apreciados pelo Congresso Nacional, em virtude do impeachment do presidente Collor, mas segundo Azevedo e Melo, a proposta estava fadada ao fracasso em virtude da intensa resistência oferecida por setores da burocracia pública - principalmente, a Receita Federal, o Ministério da Previdência e o BNDES, que possuíam divergências técnicas e temiam perder recursos,$-{ }^{6}$ pelos governos estaduais, ${ }^{7}$ que estimavam perda de arrecadação para os Estados, e pelas associações empresariais, ${ }^{8}$ que se preocupavam com a criação de novos tributos e o aumento da carga tributária.

Outro exemplo citado pelos autores é o da proposta do deputado Luiz Roberto Ponte, a chamada "emenda Ponte", de 1991. A emenda Ponte encontrou grande aceitação e simpatia nos meios empresariais - especialmente em associações empresariais - em virtude de ser uma proposta de reforma tributária baseada em impostos não sujeitos à apresentação de declaração por parte dos contribuintes. Segundo o autor da proposta, ela reduziria os custos

6 "BNDES teme perder fonte de recursos de longo prazo com extinção do PIS/PASEP" (Gazeta Mercantil, 29 jun. 1992, p. 3); “Governo faz modificações e deve enviar projeto ao Congresso amanhã” (Gazeta Mercantil, 15 jul. 1992, p. 3); "Propostas de emendas não representam consenso entre técnicos do governo" (Gazeta Mercantil, 20 jul. 1992, p. 6); "Briga barra reforma, afirma Luis Eduardo" (Folha de S.Paulo, jul. 1992).

7 "Rio Grande do Sul estima perdas em US\$ 290 milhões” (Gazeta Mercantil, 8 jul. 1992, p. 3); "Isenções e créditos do novo IVA geram oposição de secretários estaduais” (Gazeta Mercantil, 13 jun. 1992, p. 3); "Dificuldades de aprovação no Congresso" (Gazeta Mercantil, 9 jul. 92, p. 6); "Secretário da Fazenda do Paraná critica o projeto" e "Governador paulista critica falta de discussão da proposta" (Gazeta Mercantil, 21 jul. 1992, p. 7); "Federação do Comércio critica proposta do governo e faz sua própria” (Gazeta Mercantil, 24 jul. 1992, p. 3).

8 Entrevista concedida ao autor por Ary Osvaldo Mattos Filho, presidente da CERF. Cf. também “Apoio empresarial esbarra nos impostos sobre ativos e transações financeiras" (Gazeta Mercantil, 26 jun. 1992, p. 3). 
necessários para cumprimento de obrigações fiscais. Contudo, segundo Azevedo e Melo, a proposta mostrou-se inviável politicamente, vez que retirava dos estados e municípios o controle sobre os tributos, tendo em vista que, de acordo com o projeto, a União deveria concentrar a arrecadação, cabendo aos estados e municípios apenas efetuar transferências.

O próprio Banco Mundial (WORLD BANK, 1991), com base em casos anteriores de reformas tributárias em diferentes países, reconhecia que eventuais reformas devem levar em conta as condições iniciais, domésticas e estrangeiras, para que tenham algum êxito. Admitia que modificações no sistema de tributos não podem ser impostas de fora para dentro e, nessa medida, apontava como pressuposto para o sucesso o comprometimento daqueles que detêm o poder político com os propósitos da reforma.

Demais, como assevera Everardo Maciel, ex-secretário da Receita Federal:

A complexidade do nosso sistema tem raízes históricas e culturais. Não decorre meramente de atos de vontade praticados por governantes ou pelos legisladores, mas pela interação de um conjunto de forças políticas que resultaram em circunstâncias que demonstram complexidade. (MACIEL, 2010).

Isso significa que a complexidade e os defeitos do sistema têm um fundamento na realidade. Não surgiram a partir da mera vontade dos agentes políticos e, do mesmo modo, provavelmente também não serão modificados somente a partir dessa mesma vontade.

Sendo assim, seria possível traçar um paralelo entre o fracasso das reformas tributárias brasileiras e o das reformas institucionais patrocinadas pelo Banco Mundial nos anos 1980: ambas teriam desconsiderado o contexto local, a path dependence e os custos que se arca com uma mudança ampla e brusca, além de apostarem todas as fichas em grandes reformas legislativas.

A despeito do quadro negativo, a verdade não pode ser ignorada: uma reforma tributária é desejável, visto que o sistema brasileiro é demasiadamente complexo. ${ }^{9}$ Mas como melhorá-lo diante de panorama tão desanimador? Antes de tentar sugerir algumas respostas, é preciso ter contato com o contexto brasileiro e os respectivos elementos que parecem contribuir para manter a inércia institucional e emperrar o andamento das reformas. Afinal, não há texto sem contexto, nem direito sem história.

9 Como exemplo, cite-se a pesquisa realizada pela International Finance Corporation e pela empresa internacional de auditoria PricewaterhouseCoopers ( $\mathrm{PwC}$ ). Tal pesquisa busca mensurar a facilidade com que os empresários conseguem fazer negócios em cada país. No quesito "Número de horas gastas" para o cumprimento de obrigações fiscais, o Brasil ocupa a pior posição do ranking, a $183^{a}$ colocação. Segundo a $\mathrm{PwC}_{w}$, a empresa brasileira dispende anualmente 2.600 horas para cumprir com suas obrigações fiscais, mais que o dobro da penúltima colocada - a Bolívia -, onde gastam-se 1.080 horas. 
4. I A path dependence no Brasil: O QUe Dificulta A ReForma tRibutária?

As lições de Fabrício Augusto de Oliveira (1995) sobre o percurso da gestão fiscal brasileira nos últimos vinte anos iluminam o contexto político por trás do sistema tributário. Segundo o economista, talvez as principais causas para o surgimento de tantas propostas de reformas tributárias nos últimos anos residam, em primeiro lugar, no fato de que o governo federal, debatendo-se com seus desequilíbrios financeiros e incapaz de fazer um efetivo ajuste de suas contas, tem procurado resolver precariamente esse problema por meio da elevação das alíquotas de tributos não partilhados com estados e municípios, como as chamadas contribuições sociais. Isso é feito com o objetivo de evitar perdas de receitas para as esferas subnacionais.

Alguns exemplos nesse sentido foram a instituição da (já extinta) Contribuição Provisória sobre Movimentação ou Transmissão de Valores e de Créditos e Direitos de Natureza Financeira (CPMF) pela Lei 9.311/1996, da Contribuição de Intervenção no Domínio Econômico (CIDE) pelas Leis 10.168 de 2000 e 10.336 de 2001, e do recente aumento, de 0\% para 4,65\%, da alíquota combinada da Contribuição ao Programa de Integração e da Contribuição para Financiamento da Seguridade Social incidentes sobre receitas financeiras auferidas por pessoas jurídicas sujeitas ao regime de apuração não cumulativa.

$\mathrm{O}$ autor prossegue afirmando que em razão da perversidade destes tributos para o setor produtivo, os quais seguem uma lógica cumulativa, o empresariado tem se insurgido contra essa investida, amparado no argumento de que aludidos tributos distorcem o sistema de preços da economia, inibem investimentos e reduzem a competitividade dos produtos brasileiros no exterior.

Em segundo lugar, Oliveira (1995) afirma que estados e municípios, não obstante favorecidos com a ampliação dos recursos tributários resultante da descentralização de competências promovida pela Constituição de 1988, permanecem em dificuldades financeiras. Isso porque já detinham estoques de dívidas contraídas no passado, além de ter ocorrido incremento em seus gastos nos últimos anos, comprometendo-se os esforços de contenção da dívida pública.

Todos esses conflitos implicam sacrifício da população, penalização da produção e ampliação da desordem fiscal sem que o governo consiga equilibrar suas contas, subsistindo, assim, a ameaça permanente de que novas investidas tributárias possam ocorrer. Tudo isso também justifica a insatisfação dos contribuintes que efetivamente arcam com o ônus da tributação, diante da profusão de tributos, da complexidade de sua legislação e das manobras jurídicas praticadas pelo poder público para, frequentemente, modificar a interpretação das regras do jogo com o intuito de aumentar a arrecadação.

Note-se, diante do exposto, que é possível afirmar que há um cenário de tensão e desconfiança mútua entre estados, municípios, governo federal e sociedade. Além desse diagnóstico ser referendado em diversos textos de estudiosos da reforma tributária no Brasil, ${ }^{10}$ o que 
demonstra ser conclusão relativamente incontroversa entre os especialistas, tal percepção é corroborada quando se analisa os depoimentos dos principais atores envolvidos com a questão da reforma tributária.

A despeito de os entrevistados representarem apenas uma pequena amostra dos atores envolvidos com o tema da reforma tributária, o fato de o diagnóstico a respeito da falta de confiança se repetir na fala de vários entrevistados - como se verá abaixo - e, também, em textos redigidos por alguns dos maiores especialistas no assunto no Brasil, permite afirmar com relativa segurança que esse é um dos principais obstáculos à reforma, muito embora provavelmente existam outros empecilhos e questões que mereçam análise detida.

No estudo "Reforma tributária viável: simplificação, transparência e eficiência - relato das pesquisas realizadas pelo NEF no ano de 2010”, confeccionado pelo Núcleo de Estudos Fiscais da Escola de Direito de São Paulo da Fundação Getulio Vargas (2010), foram realizadas catorze entrevistas com técnicos das secretarias da Fazenda dos estados federados, representantes e especialistas de confederações e federações de empresas, entidades representativas do fisco, economistas e advogados especializados no assunto.

De acordo com o relatório, a falta de confiança foi mencionada espontaneamente em quase todas as entrevistas como um dos maiores empecilhos à reforma. Essa desconfiança é gerada principalmente pela denominada guerra fiscal entre os estados. ${ }^{11}$ Conforme o estudo, oito entrevistados centraram espontaneamente sua fala em problemas referentes à guerra fiscal e ao Imposto sobre operações relativas à Circulação de Mercadorias e sobre prestações de Serviços de transporte interestadual, intermunicipal e de comunicação (ICMS), dizendo que estes seriam os grandes nós da reforma. Todos os entrevistados consideram que o medo dos estados de perder arrecadação é, de fato, um dos grandes entraves à reforma. Foi dito ainda que não há dados confiáveis a respeito de quanto cada estado poderia perder com uma reforma, e tal incerteza aumenta a desconfiança entre aqueles entes.

Em uma das primeiras entrevistas realizadas foi relatado que projetos reformistas provavelmente fracassarão se as modificações propostas implicarem perda de competência mesmo que mínima - dos estados. Por exemplo, de acordo com um entrevistado ligado à Secretaria da Fazenda de um estado, a solução que propunha a criação de um Imposto sobre Valor Agregado (IVA) nacional foi mal recebida por acarretar maior concentração de poder nas mãos da União. Afirmou-se, ainda, que os estados não querem ser tolhidos da possibilidade de negociar a concessão de incentivos fiscais.

Chamou-se atenção, com frequência, para o grande poder detido pelos técnicos da Fazenda e afirmou-se que muitas reformas são inviabilizadas por eles. Reformas que ensejam

11 Trata-se de fenômeno que consiste na exacerbação de práticas competitivas entre entes de uma mesma federação em busca de investimentos privados mediante o oferecimento de benesses fiscais atrativas que incentivariam a migração de agentes privados entre os diversos estados. 
aumento de custos e maior dificuldade na arrecadação geralmente são barradas por essa classe de servidores públicos. Enfatizou-se, ainda, que são os mesmos servidores que há muitos anos atuam no Conselho Nacional de Política Fazendária (Confaz) e que também esse é um obstáculo a mudanças.

Da fala dos entrevistados, é possível inferir, ademais, que o governo federal, em certas circunstâncias, posiciona-se como mediador do conflito entre os estados e, outras vezes, atua como defensor dos próprios interesses, em confronto com os dos estados. A ambiguidade do posicionamento do governo federal apareceu de maneira relevante nas entrevistas. $\mathrm{O}$ tema foi explorado em todas elas e verificou-se, assim, que há consenso em torno da ideia de que a reforma tributária nunca foi uma prioridade do governo federal. Alguns entrevistados afirmaram que essa falta de interesse na promoção de uma reforma se deve ao fato de que a União não passa por grandes dificuldades financeiras, uma vez que possui a prerrogativa prevista na Constituição Federal de criar contribuições sociais.

Quanto aos municípios, um dos entrevistados mencionou que estes não têm tido seus interesses contemplados nas propostas reformistas. Segundo ele, os municípios não possuem força suficiente no processo de negociação: serão vítimas no caso de aprovação ou permanecerão em desvantagem - como já estão - no caso de não aprovação.

Com relação ao empresariado, houve menção a duas formas de atuação: há as empresas que são beneficiadas com incentivos fiscais e, de outro lado, o empresariado em geral, que tem grande interesse na reforma. Foi dito que os primeiros frequentemente pressionam os estados pela manutenção do status quo ou clamam por garantias de que os benefícios sejam mantidos, em caso de reforma. Quanto ao segundo grupo, de acordo com um entrevistado ligado a uma confederação de empresários, o núcleo rígido é formado por Federação das Indústrias do Estado de São Paulo (Fiesp), Confederação Nacional da Indústria (CNI), Confederação Nacional da Agricultura (CAN) e Federação Brasileira de Bancos (Febraban). Um entrevistado sugeriu, ainda, a existência de um terceiro grupo de empresários ligados ao setor de serviços, os quais são representados principalmente pela Confederação Nacional de Serviços (CNS) e pela Confederação Nacional de Turismo (CNTur). ${ }^{12}$ Tal grupo também teria interesse na reforma, mas focaria suas reinvindicações na questão da desoneração da folha de pagamentos. Desse modo, esse subgrupo do empresariado estaria próximo da classe trabalhadora, que possui anseios similares.

A despeito disso, um dos entrevistados comentou que percebe que órgãos de classe tanto de empresários como de trabalhadores - não entrelaçam de forma consistente seus discursos e, por isso, tendem a atuar isoladamente. Faltaria, portanto, uma atuação coesa em defesa dos interesses desses grupos.

12 Os resultados de tal entrevista foram extraídos do relatório de pesquisa de 2010 do Núcleo de Estudos Fiscais, citado anteriormente. 
Em suma, pode-se sintetizar em quatro pontos as principais conclusões atingidas por meio das entrevistas realizadas pelo NEF (2010):

a) é politicamente inviável realizar uma reforma tributária abrangente em um curto prazo;

b) a reforma tributária não parece ter sido uma prioridade do governo federal (alguns entrevistados chegaram a argumentar que essa foi a principal razão do insucesso das propostas reformistas nos últimos vinte anos);

c) em que pese a existência de empresas que preferem a manutenção das condições atuais por serem beneficiadas com incentivos fiscais, o empresariado, em geral, é a favor da reforma. Entretanto, aparentemente esse grupo não consegue coordenar seus interesses em prol de um único projeto e alinhar-se em torno de um esforço continuado para sua implementação;

d) a falta de confiança entre os estados brasileiros pode ser considerada o grande entrave para a viabilização política de uma reforma tributária. Além do medo da perda de arrecadação, os estados temem perder o poder de fazer política tributária - foi dito que receiam, sobretudo, não poderem mais conceder incentivos e preocupam-se com as repercussões eleitorais de tal impedimento.

Portanto, as entrevistas realizadas pelo Núcleo de Estudos Fiscais, em conjunto com textos produzidos por alguns dos principais estudiosos brasileiros sobre o tema, parecem apontar que um dos principais obstáculos à realização de uma reforma tributária no Brasil é de cunho político. O próprio Banco Mundial (WORLD BANK, 1991), com base em experiências anteriores, propugnava que reformas tributárias carecedoras de apoio político muito dificilmente são exitosas.

Em acréscimo, há de se ressaltar outro aspecto político que desestimula o acontecimento de reformas. A arrecadação tributária nos últimos anos vem aumentando continuamente: de 2001 a 2010 cresceu, em termos brutos, 264,49\% e, descontando a inflação, o incremento foi de $92,03 \% .^{13}$ Uma parte desse aumento constante se deve ao desenvolvimento econômico do país, mas uma fatia desse crescimento é fruto da manipulação da interpretação da legislação tributária por parte dos fiscos nos vários níveis federativos.

Um caso emblemático é o do aproveitamento do ágio gerado em operações de fusão, incorporação ou cisão para dedução de imposto de renda. Como explica Eliseu Martins (2012), com

13 Disponível em: <http://www2.uol.com.br/canalexecutivo/notas11/1502201116.htm>. Acesso em: 17 out. 2012. 
o objetivo de aumentar o valor de suas empresas no processo de desestatização, o governo não poupou esforços para obter a aprovação da Lei n. 9.532/1997, pela qual se passou a aceitar a dedutibilidade da amortização do ágio em cinco anos, desde que mediante processo de fusão, incorporação ou cisão. Em acréscimo, editou-se a Medida Provisória n. 66/2002 (que se tornou a Lei n. 10.637/2002), pela qual se permitiu ao vendedor diferir o ganho obtido por esse ágio. No entanto, com o valor dessas dedutibilidades assumindo proporções vultosas, recentemente o Fisco começou a autuar as empresas sob os mais variados argumentos, nas mais diversas situações.

Outra discussão na qual sobreleva-se a mudança de intepretação acerca da legislação tributária diz respeito à incidência (ou não) de ICMS sobre a veiculação de material publicitário em sítios eletrônicos de provedores de internet. Sabe-se que o ICMS incide sobre operações relativas à circulação de mercadorias e sobre prestações de serviços de transporte interestadual e intermunicipal e de comunicação. Porém, o que pode ser considerado exatamente um serviço de comunicação? A veiculação de material publicitário estaria abrangida pela aludida hipótese de incidência?

Até 30 de julho de 2003 o Imposto sobre Serviços de Qualquer Natureza (ISS) incidia sobre essa atividade, conforme constava no item 86 da lista anexa ao Decreto-Lei n. 406/68, acrescentado pela Lei Complementar (LC) n. 56/87. Entretanto, com a promulgação de nova lista de serviços, por meio da LC n. 116/03, essa atividade foi objeto de veto pela Presidência da República, com base em parecer técnico do Ministério da Justiça, tendo como justificativa a incompetência do ente municipal para tributar serviços de comunicação, que seriam de competência estadual.

A referida alteração legislativa, combinada com o fundamento do veto governamental, atraiu a atenção dos entes estaduais, que viram na tributação dessa atividade, mediante o ICMS- Comunicação, uma potencial fonte de receitas tributárias. Para tanto, seria necessário enquadrar a veiculação de material publicitário na internet como "serviço de comunicação". Diante disso, diversas autuações fiscais foram lavradas, retroativamente, com amparo do prazo decadencial de cinco anos, para cobrar o ICMS-Comunicação de provedores de acesso à internet que, historicamente, eram contribuintes do ISS e nunca haviam sido orientados a recolher o ICMS-Comunicação.

Não bastasse isso, alguns entes municipais continuaram exigindo o ISS do contribuinte prestador de tal atividade, passando a enquadrar o serviço de veiculação de material publicitário na hipótese de incidência prevista para a atividade de publicidade e propaganda ou de agenciamento de publicidade, serviços que continuaram previstos na nova lista anexa introduzida pela LC n. 116/03.

Tais exemplos nos permitem sugerir dois motivos que facilitam a manipulação da intepretação das normas tributárias: i) a grande complexidade do sistema decorrente da volumosa profusão de normas e; ii) a falta de transparência do sistema, marcado pelo desconhecimento dos critérios interpretativos do Fisco, o que acaba por ofuscar o debate público acerca 
de questões tributárias e o controle social da arrecadação tributária. Outro elemento que reforça isso é a falta de transparência do tributo para o contribuinte de fato. Boa parte da população brasileira não sabe que paga tributo ou tem pouquíssima familiaridade com o sistema tributário. ${ }^{14}$

Portanto, podem ser apontados dois problemas principais, ambos de natureza política, que explicam a inocorrência de ampla reforma tributária no país: a falta de coesão entre os diversos entes federativos e a ausência da participação do cidadão nesse processo, que é quem verdadeiramente paga a conta dos tributos.

O panorama acima dá ideia de quão controverso é o tema da reforma tributária no país e do tamanho do desafio para a realização de modificação estrutural do sistema de tributos. A seguir, sugerem-se algumas alternativas absolutamente despretensiosas que poderiam auxiliar na obtenção de resultados mais satisfatórios no futuro.

\section{CONSIDERAÇÕES FINAIS: ALGUMAS ALTERNATIVAS VIÁVEIS}

Viu-se que o principal problema da reforma tributária no Brasil não é de divergência técnica, mas sim de falta de coesão política e de discussão e interesse social acerca do tema. Assim, acredita-se que propostas ambiciosas que pretendam modificar radicalmente e de uma só vez o sistema tributário estão fadadas ao insucesso, ainda que as posições políticas sejam declaradas e negociadas abertamente. O histórico de fracasso das reformas aponta nesse sentido, e a falta de cenário político e social minimamente coeso e engajado também são grandes obstáculos. Inobstante, há estratégias que podem contribuir efetivamente para o processo de reforma, tais como a reprodução de boas práticas, o experimentalismo incremental e o bypass institucional.

Consoante salienta Santi (2012), um exemplo de sucesso de reforma no Brasil é o do Simples Nacional (SN). Trata-se de regime tributário simplificado elaborado para micro e pequenas empresas que unifica a cobrança dos tributos federais, estaduais e municipais por uma única via. Ressalte-se que o SN veio a aumentar e aprimorar o regime do Simples Federal, que não incluía tributos estaduais e municipais.

14 Cerca de $22,5 \%$ da população não sabe identificar o nome de pelo menos um tributo específico. Disponível em: <http://economia.uol.com.br/ultimas-noticias/infomoney/2010/10/27/mais-de22-da-populacao-nao-conhece-impostos-que-paga.jhtm $>$. Acesso em: 21 nov. 2012. A maioria da população tem conhecimento de que paga impostos sobre produtos de consumo doméstico. No entanto, não faz a menor ideia de quanto paga de tributos sobre cada mercadoria ou serviço. Disponível em: $<$ http: / / economia.estadao.com.br/noticias/ economia,brasileiro-nao-sabe-quanto-paga-de-impostodiz-fiesp, 17403,0.htm>. Acesso em: 21 nov. 2012. Essas preocupações ensejaram a edição da Lei $n$. 12.741, de 2012, que determina que os valores aproximados dos tributos incidentes sobre mercadorias e serviços sejam discriminados nas notas fiscais emitidas aos consumidores. 
Note-se que o exemplo combina diferentes estratégias de reforma. Primeiramente, o Simples foi uma espécie de bypass, porque não obrigou o micro e pequeno empresário a adotar tal regime. Foi uma opção dada a esse tipo de contribuinte, coexistindo com a forma de tributação regular. Hoje, provavelmente, poucos empresários que se encontrem em condições de usufruir do regime simplificado optarão pelo regime normal, o que comprova o sucesso da estratégia. Além disso, como exposto, o Simples não nasceu com todas as características que possui hoje. Foi uma reforma gradual e experimental, pois começou com apenas parte dos tributos do sistema. Após o sucesso inicial e comprovado o funcionamento da sistemática, a reforma foi ampliada, incluindo-se tributos estaduais e municipais. A pergunta que fica para os formuladores de política tributária é: em que medida o modelo do Simples poderia ser utilizado para simplificar as obrigações acessórias dos contribuintes de maior porte?

Outro exemplo interessante é o do Programa Nota Fiscal Paulista, que, segundo dados publicados no sítio eletrônico da Fazenda do Estado de São Paulo, devolve a seus consumidores até 20\% do ICMS efetivamente recolhido pelo estabelecimento comercial. É um incentivo para que os cidadãos que adquirem mercadorias exijam do estabelecimento o cupom fiscal. Os consumidores que informarem seu número no Cadastro de Pessoas Físicas (CPF) ou no Cadastro Nacional da Pessoa Jurídica (CNPJ), no momento da compra, podem receber os créditos e ainda concorrem a prêmios em dinheiro. Segundo Bruno Paschoal (2012), o programa conseguiu atender a interesses de diferentes atores: do estado, já que o programa aparentemente aumenta a arrecadação tributária; da Fazenda Pública, que ganhou novos mecanismos fiscalizatórios, dos quais se destaca o banco de dados que foi criado com as informações enviadas pelos estabelecimentos comerciais; do contribuinte de fato, ou seja, dos cidadãos em geral, que são beneficiados com reembolsos e prêmios em dinheiro; e dos próprios estabelecimentos comerciais, que tiveram algumas de suas obrigações acessórias reduzidas.

Ademais, de acordo com a pesquisa de Paschoal, a Nota Fiscal Paulista foi totalmente baseada em programa similar que vinha sendo implementado pela prefeitura de Angra dos Reis, no Rio de Janeiro. "Era preciso apenas transplantá-lo e adaptá-lo à realidade paulistana. Não que isso fosse simples; as diferenças entre o número de prestadores e tomadores de serviço em Angra dos Reis e São Paulo é gritante” (PASCHOAL, 2012, p. 8). Embora não seja possível apontar com clareza quais critérios devem ser observados para a realização desse “transplante adaptado", no caso da Nota Fiscal Paulista pode-se imaginar que um ponto de atenção deve ter sido o número de estabelecimentos emissores de notas fiscais vis-à-vis à estrutura de pessoal e de equipamento de que dispõe o fisco paulista. Isto é, o programa só seria útil se o fisco tivesse condições de administrar o número de novos contribuintes que seriam registrados em seu banco de dados.

Outra questão que deve ter sido analisada foi a da familiarização da população com o programa. Seriam necessárias campanhas abrangentes para introduzir e familiarizar prestadores e tomadores de serviços acerca dos procedimentos e benefícios do programa. Assim, provavelmente as autoridades competentes devem ter refletido a respeito da necessidade de 
se separar verbas destinadas a campanhas publicitárias para a implementação do programa em São Paulo.

Veja-se, portanto, que o programa foi importado de outro local em que já funcionava, fazendo-se as devidas adaptações para a realidade paulista. Em vista disso, por que não implementar programas similares ao da Nota Fiscal Paulista em outras localidades?

Iniciativas como essas têm de ser estimuladas. Deve-se buscar outros instrumentos eficientes que existem no sistema pátrio e procurar replicá-los e ampliá-los, assim como foi feito com o Simples e a Nota Fiscal Paulista. Mecanismos inovadores também podem ser implementados pela estratégia do bypass. Instituições do sistema que não funcionam bem devem ser gradualmente modificadas a partir do experimentalismo incremental.

Diante de todo o exposto, não é temerário afirmar que a PEC 233/2008, por mais interessantes e benéficas que possam ser as modificações por ela propostas, provavelmente terá a mesma sorte das tentativas de reforma estrutural predecessoras. Tal proposta pretende, sinteticamente: 1) criar um IVA federal, unificando as contribuições sociais; 2) extinguir a Contribuição Social sobre Lucro Líquido (CSLL); 3) instituir novo ICMS, com legislação federal e alíquotas uniformes; etc. A proposta de criação de um ICMS nacional, por exemplo, dificilmente será aprovada no Legislativo. A resistência política dos estados provavelmente seria intensa, e as experiências anteriores comprovam isso.

Sem embargos do exposto, é de se destacar novamente a necessidade de reforma tributária no país. Uma reforma viável, que não nasça predestinada ao fracasso. E, para ter êxito nessa empreitada, não se pode olvidar a lição encampada por Eurico de Santi:

Reforma fiscal não é um projeto de lei ou emenda constitucional, um pedaço de papel, é um processo de reconstrução de nossa identidade que exige a tomada de consciência sobre fatos políticos, econômicos, jurídicos e crenças que definem o pacto federativo e determinam o papel do Estado e da participação do cidadão nos rumos das políticas públicas. (SANTI, 2012, p. 54, grifos nossos).

Richard Bird, que atuou como economista do Fundo Monetário Internacional e do Banco Mundial realizando e estudando reformas tributárias em dezenas de países, também explica que a reforma tributária é muito mais que uma proposta legislativa:

Reforma tributária requer um campeão viável e politicamente relevante que assuma a reforma e seja capaz de "vendê-la". Aparência também importa. "Vender" a reforma depende não apenas do conteúdo da política pública, mas também de como ela é apresentada. Isso é verdade porque percepção é realidade em uma extensão considerável no mundo da política. Sem benefícios visíveis que se sobreponham aos custos visíveis da tributação, novas políticas tributárias provavelmente não serão aceitas (mesmo que elas sejam melhores do que as políticas que pretendem substituir). Finalmente, detalhes 
importam. O destino da política pública pode ser alterado de acordo com o modo que determinados grupos particulares percebem que seus interesses serão afetados pela proposta de reforma tributária. ${ }^{15}$ (BIRD, 2010, p. 4).

Os exemplos de outros países reforçam esse entendimento. Conforme relatório do Banco Mundial (WORLD BANK, 1991), reformas exitosas geralmente envolvem a análise do sistema tributário como um todo, ou seja, tanto da administração tributária quanto do sistema de tributos em si. Sendo assim, englobam uma gama de fatores que vão além de redigir proposta legislativa de qualidade e passam por treinar funcionários da administração tributária, bem como melhorar a gestão e a infraestrutura de órgãos públicos ligados à questão tributária. Tais medidas levam tempo para serem implementadas e para surtirem efeitos. Além disso, nenhuma reforma pode solucionar todos os problemas existentes, de uma só vez. Reformas de relativo sucesso como aquelas levadas a cabo na Indonésia, na Jamaica e no Malawi, na década de 1980, envolveram substancial preparação e arranjos transitórios, inclusive consultas às partes afetadas, como o próprio contribuinte. A reforma jamaicana, por exemplo, foi anunciada em 1983 e ainda em 1991 havia medidas sendo implementadas. Não bastasse isso, essas experiências também exigiram continuidade por parte dos tomadores de decisões chave, responsáveis pela gestão econômica do país e também pela promoção de campanhas educacionais para introduzir as propostas na sociedade e familiarizar os contribuintes com as novidades.

Embora não se pretenda descrever minuciosamente os processos de reforma ocorridos nos referidos países, pode-se extrair alguns pontos interessantes da breve descrição acima desenhada: (i) reformas não se fazem da noite para o dia; (ii) participação política e popular são fatores relevantes e; (iii) reformas não dependem apenas de alteração legislativa, mas envolvem grande espectro de medidas, como mudança de arranjos institucionais e da práxis de funcionários públicos.

Isso nos permite afirmar, na linha defendida pelo ex-secretário da Receita Federal Everardo Maciel, ${ }^{16}$ que é praticamente impossível que grandes mudanças legislativas tenham o condão de modificar o sistema tributário de maneira positiva, pelo menos no atual cenário

Tradução livre do seguinte trecho: "Tax policy reform requires a viable and politically relevant champion who owns the reform and can sell it. Packaging also matters. Selling reform depends not only on the contents of the policy package, but also on how it is presented. This is true because perception is reality to a considerable extent in the world of politics. Without visible benefits to offset the visible costs of taxation, new tax policies are unlikely to be accepted (even if they are technically better than the policies they replace). Finally, details matter. The fate of a policy may turn on how some particular group perceives its interests to be affected or on the precise sequencing and scope of reform”. impossiveis_115897.html>. Acesso em: 18 out. 2012. 
político brasileiro. Tal intento só se consegue com iniciativas realistas, criativas e de longo prazo, que gradualmente procurem alterar a realidade brasileira.

\section{REFERÊNCIAS BIBLIOGRÁFICAS}

AZEVEDO, Sérgio de; MELO, Marcus André. A política da reforma tributária: federalismo e mudança constitucional. Revista Brasileira de Ciências Sociais, v. 12, n. 35, 1997. Disponível em: <http: / /www. scielo.br/scielo.php?pid=S0102-69091997000300006\&script $=$ sci_arttext $>$. Acesso em: 16 abr. 2015 .

BARRETO, Aires Fernandino. Tributação e conjuntura nacional. In: (Coord.). Segurança jurídica na tributação e Estado de direito. São Paulo: Noeses, 2005.

BIRD, Richard. Taxation and Development. Economic Premise, n. 34, 2010. Disponível em: <http:// siteresources.worldbank.org/INTPREMNET/Resources/EP34.pdf>. Acesso em: 25 abr. 2013.

BORGES, José Souto Maior. Desequilíbrios regionais e reforma tributária. Revista de Direito Tributário, n. 33, p. 50-63, 1985.

BORGES, José Souto Maior. A Reforma Tributária: seus modelos e sua crítica. In: SANTI, Eurico M. D. de (Coord.). Tributação e desenvolvimento: homenagem ao professor Aires Barreto. São Paulo: Quartier Latin, 2011. (Tributação e Desenvolvimento), p. 383-388.

EVANS, Peter. Embedded Autonomy: states and industrial transformation. New Jersey: Princeton Press, 1995.

LIMA, Edilberto Carlos Pontes. Reforma Tributária no Brasil: entre o ideal e o possível. Texto para Discussão n. 666. Brasília: Ipea, 1999.

MACIEL, Everardo. Reforma tributária sempre piora o que já existe. Revista Eletrônica Consultor Jurídico, 14 fev. 2010. Entrevistadora: Aline Pinheiro. Disponível em: <http://www.conjur.com.br/2010-fev14/entrevista-everardo-maciel-ex-secretario-receita-federal>. Acesso em: 19 maio 2012.

MARTINS, Eliseu. Dedutibilidade fiscal da amortização do ágio. Disponível em: <https: / / conteudo clippingmp.planejamento.gov.br/cadastros/noticias/2012/8/28/dedutibilidade-fiscal-da-amortizacao -do-agio >. Acesso em: 23 out. 2012. 
MILHAUPT, Curtis; PISTOR, Katharina. Law and Capitalism: what corporate crises reveal about legal systems and economic development around the world. Chicago: Chicago Press, 2008.

NORTH, Douglass. Institutions, institutional change and economic performance. Cambridge: Cambridge University Press, 1990.

NÚCLEO DE ESTUDOS FISCAIS. Reforma Tributária Viável: simplificação, transparência e eficiência. Relato das pesquisas realizadas pelo NEF no ano de 2010. São Paulo: Escola de Direito de São Paulo da Fundação Getulio Vargas, 2010.

OLIVEIRA, Fabrício Augusto de. Crise, reforma e desordem do sistema tributário nacional. Campinas: Unicamp, 1995.

PASCHOAL, Bruno. A arquitetura da Nota Fiscal Paulista: a ideia, o esboço, o projeto, e a obra. Artigo apresentado para aprovação na disciplina de Estado, Desenvolvimento e Regulação, ministrada pelo Prof. Carlos Ari Sundfeld no mestrado da FGV Direito SP, jan. 2012. Mimeo.

PRADO, Mariana. Institutional bypass: an alternative for development reform. Social Science Research Network, abr. 2011. Disponível em: <http://papers.ssrn.com/sol3/papers.cfm?abstract_id=1815442>. Acesso em: 25 abr. 2013.

PRADO, Mariana; TREBILCOCK, Michael. Path dependence, development and the dynamics of institutional reforms. University of Toronto Law Journal, v. 59, n. 3, 2009.

REZENDE, Fernando. Conflitos federativos e reforma tributária. In: REZENDE, Fernando (Coord.). Desafios do Federalismo Fiscal. Rio de Janeiro: FGV, 2006.

RODRIK, Dani; SUBRAMANIAN, Arvind. The primacy of institutions (and what this does and does not mean). Finance \& Development. Washington: International Monetary Fund, 2003. Disponível em: <http://www.imf.org/external/pubs/ft/fandd/2003/06/pdf/rodrik.pdf>. Acesso em: 29 fev. 2012.

SANTI, Eurico M. D. de. Reforma tributária: reconstruindo os laços nacionais do federalismo brasileiro e resgatando a dignidade do contribuinte. In: LIMA, Maria Lúcia L. M. P. Direito e economia: 30 anos de Brasil. São Paulo: Saraiva, 2012. p. 54-76. t. 3. (Série GVlaw).

SANTI, Eurico M. D. de (Coord.). Tributação e desenvolvimento: homenagem ao professor Aires Barreto. São Paulo: Quartier Latin, 2011. (Tributação e Desenvolvimento).

SCHAPIRO, Mario;TRUBEK, David. Redescobrindo o Direito e Desenvolvimento: experimentalismo, 
pragmatismo democrático e diálogo horizontal. In: (Org.). Direito e Desenvolvimento: um diálogo entre os Brics. São Paulo: Saraiva, 2012.

SWEDBERG, Richard. Max Weber e a ideia de sociologia econômica. Tradução Dinah Abreu Azevedo. Rio de Janeiro: UFRJ, 2005.

TAMANAHA, Brian Z. O primado da sociedade e as falhas do Direito e Desenvolvimento. Rev. direito GV, São Paulo, v. 6, n. 1, p. 175-212, jun. 2010.

VIEIRA, José Roberto. Direitos fundamentais e reforma tributária: esse obscuro e ardiloso objeto do desejo. In: SANTI, E. M. D. de (Coord.). Tributação e Desenvolvimento: homenagem ao professor Aires Barreto. São Paulo: Quartier Latin, 2011. (Tributação e Desenvolvimento).

WORLD BANK. Lessons of tax reform. Washington: World Bank, 1991.

Daniel Leib Zugman Mestre em Direito e Desenvolvimento pela Escola de Direito de São Paulo da Fundação Getulio Vargas.

Advogado em São Paulo.

zugmandoutlook.com 